\title{
Smart materials activation analysis on example of nickel and titanium alloys
}

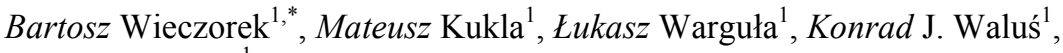 \\ Klaudia Wiesner $^{1}$ \\ ${ }^{1}$ Poznan University of Technology, Chair of Basic of Machine Design, Piotrowo Street 3, 60-965 \\ Poznan, Poland
}

\begin{abstract}
This paper is focused on research concerning activation time of elements made of Ni-Ti alloy (55/45\% vol.) The activation time is a period of time required for alloy to reach it's austenitic transformation (Af) temperature. For examined wire it reached values up to $60{ }^{\circ} \mathrm{C}$. Heating of NiTi wire was conducted by retaining heat. In this paper the influence of wire length and electric current power on heating time is presented. This research allows to determine the correlation between the increase of temperature and time. For given electric current values. This data is useful for effective design of SMA actuators..
\end{abstract}

Keywords: NiTinol, shape memory materials, activation, short circuit, austenitic transformation

\section{Indrotuction}

The need for miniaturisation of actuators (effectors) used in mechatronic systems calls for innovative engineering materials. Examples of such materials are Shape Memory Alloys (SMA) [1]. These materials remember and recover the programmed shape under certain external stimuli, such as a change of temperature or magnetic field. One of the most widely known SMA's is nitinol - a material developed by Bühler in 1962 [2] and patented, together with Wiley, in 1965 [3]. Nickel and titanium alloys feature so-called mechanical memory. The shape memory effect in nickel and titanium alloys can be attributed to their phase structure which at higher temperatures is made up of $\beta$-phase with the B2 lattice. This structure is transformed into transitional R-phase with rhombohedral crystal lattice at the temperature above the martensite start temperature $\mathrm{Ms}$, followed by transformation to martensitic structure with monoclinically distorted B19 lattice The reverse transformation takes place without R-phase transition i.e. martensite returns directly to $\beta$-phase with B3 lattice. The austenite finish temperature (Af) depends on the chemical composition of alloy and can vary over the range of $-150^{\circ} \mathrm{C}$ to $+150^{\circ} \mathrm{C}[1]$.

An example application of SMA materials in mechatronic systems are nitinol pull-type springs. Springs of this type are tensioned under external force. When heated up to the

\footnotetext{
* Corresponding author: bartosz.wieczorek@put.poznan.pl

Reviewers: Eva Tillová, Marta Kianicová
} 
temperature Af the spring returns to the programmed shape, as a result of reverse transformation of martensite to austenite.

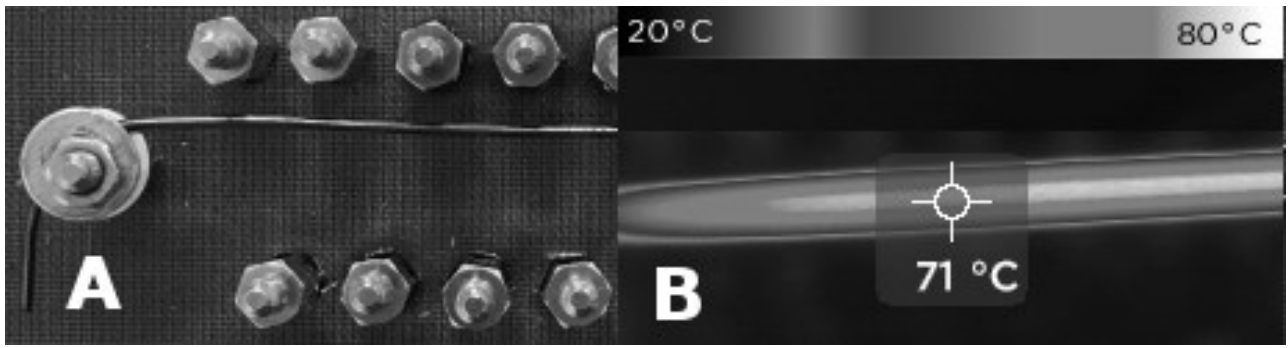

Fig. 1. View of the test specimen mounted in the test stand (A) and thermal image of $100 \mathrm{~mm}$ long Ni-Ti wire during heating (B)

The austenite finish temperature (Af) of the analysed alloy was ca. $60^{\circ} \mathrm{C}$ [4]. The easiest way to obtain such temperature is by using the test specimen as a resistor and thus increase the temperature of the wire by passing current. Uneven distribution of temperature in the initial phases of heating is a disadvantage of this method (Fig. 1).

\section{Test procedure}

The objective of these experiments was to investigate the effect of the duration of flow of electric current through the Ni-Ti alloy wire on its final temperature. The effect of the current on the time needed to reach the Af temperature was also investigated. The test specimens were prepared from $1 \mathrm{~mm} \mathrm{Ni-Ti} \mathrm{wires} \mathrm{in} \mathrm{two} \mathrm{different} \mathrm{lengths,} \mathrm{supplied} \mathrm{from} \mathrm{a}$ regulator providing controlled current and voltage values (Table 1). For comparison $33 \mathrm{~mm}$ long controls were made of the same wire.

Table 1. Current and voltage values for the respective specimens

\begin{tabular}{|c|c|c|c|c|c|c|c|}
\hline \multicolumn{7}{|c|}{ Specimen material: $1 \mathrm{~mm}$ wire of nickel-titanium alloy $(55 \% \mathrm{Ni}$ and $45 \% \mathrm{Ti})$, Af } \\
temperature of $60^{\circ} \mathrm{C}$ \\
\hline \multicolumn{7}{|c|}{$\mathbf{L}=\mathbf{1 0 0}[\mathbf{m m}]$} & \multicolumn{5}{c|}{$\mathbf{L}=\mathbf{6 6}[\mathbf{m m}]$} \\
\hline $\mathrm{I}[\mathrm{A}]$ & $\mathrm{U}[\mathrm{V}]$ & $\mathrm{P}[\mathrm{W}]$ & $\Delta \mathrm{P}[\mathrm{W}]$ & $\mathrm{I}[\mathrm{A}]$ & $\mathrm{U}[\mathrm{V}]$ & $\mathrm{P}[\mathrm{W}]$ & $\Delta \mathrm{P}[\mathrm{W}]$ \\
\hline 5.5 & 1.2 & 6.60 & 0.67 & 5.5 & 1.0 & 5.50 & 0.65 \\
\hline 6.0 & 1.3 & 7.80 & 0.73 & 6.0 & 1.1 & 6.60 & 0.71 \\
\hline 6.5 & 1.5 & 9.75 & 0.80 & 6.5 & 1.2 & 7.80 & 0.77 \\
\hline 7.0 & 1.6 & 11.20 & 0.86 & 7.0 & 1.4 & 9.80 & 0.84 \\
\hline 7.5 & 1.7 & 12.75 & 0.92 & 7.5 & 1.5 & 11.25 & 0.90 \\
\hline 8.0 & 1.8 & 14.40 & 0.98 & 8.0 & 1.6 & 12.80 & 0.96 \\
\hline 8.5 & 1.9 & 16.15 & 1.04 & 8.5 & 1.7 & 14.45 & 1.02 \\
\hline 9.0 & 2.0 & 18.00 & 1.10 & 9.0 & 1.8 & 16.20 & 1.08 \\
\hline 9.5 & 2.1 & 19.95 & 1.16 & 9.5 & 2.0 & 19.00 & 1.15 \\
\hline
\end{tabular}

Where: $\mathrm{L}$ - length of tested wire, $\mathrm{I}$ - current, $\mathrm{U}$ - voltage, $\mathrm{P}$ - power, $\Delta \mathrm{P}$ - power measurement uncertainty.

The test stand was based on textolite plate acting as an insulator and used for mounting wires of the specified lengths. Power was supplied by Voltcraft PS 1440 benchtop power supply unit, connected to the test specimen by cables. The last element of the test stand was 
the Reveal PRO thermal imaging camera from Seek thermal whose role was to record the variation of temperature of the tested wire (Fig. 2).

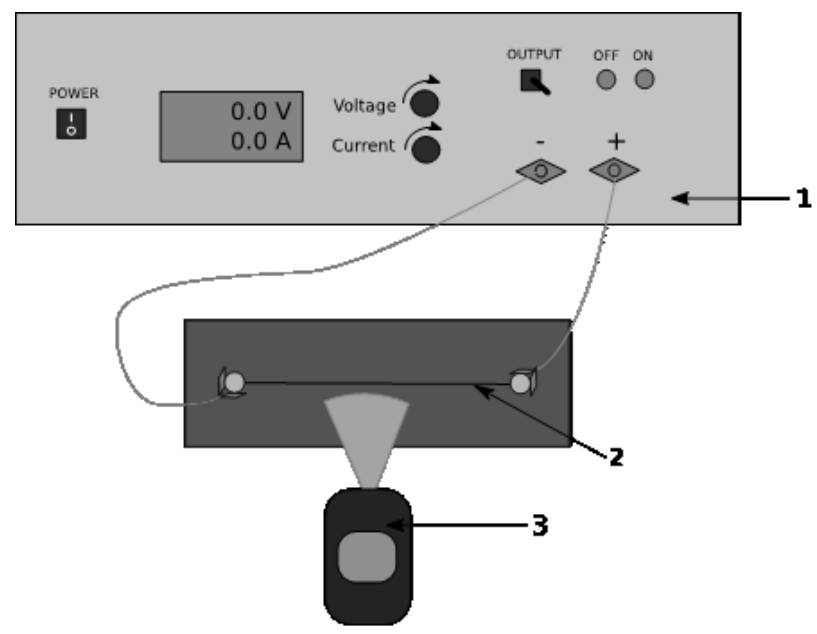

Fig. 2. Test stand setup: 1 - Voltcraft PS 1440 benchtop power supply, 2 - specimen of NiTi wire, 3 - Reveal PRO thermal imaging camera

According to the test procedure, specimens of different lengths were mounted on the textolite base plate. Then the electricity was applied at the specified current and voltage levels. For each power level the heating process was repeated five times. The time needed to increase the wire temperature from $24^{\circ} \mathrm{C}$ to ca. $70^{\circ} \mathrm{C}$ was the measured parameter.

\section{Results of experiments}

The research program comprised series of tests performed on Ni-Ti wires of different lengths, namely $33 \mathrm{~mm}, 66 \mathrm{~mm}$ and $100 \mathrm{~mm}$. All the test specimens were made of straight sections of $1 \mathrm{~mm}$ wire. Examples of time-temperature curves are presented in Fig. 3.

The experimental results were used to determine the time needed to increase the temperature of wire made of Ni-Ti alloy up to the activation temperature of ca. $70^{\circ} \mathrm{C}$. The analysis of results started with determining of effect of the wire length on the time needed to increase the specimen temperature to Af (Fig. 3). The results allow us to conclude that the length of wire has a significant effect on the length of time needed to reach the activation temperature. The values recorded at $6,6 \mathrm{~W}$ power input were: ca. $45 \mathrm{sec}$. for 100 $\mathrm{mm}$ length, ca. $22 \mathrm{sec}$. for $66 \mathrm{~mm}$ length and ca. $35 \mathrm{sec}$. for $33 \mathrm{~mm}$ length. With the shortest specimens $(33 \mathrm{~mm})$ the whole test set-up acted as a radiator transferring heat to the environment. As a result, it took longer to heat up the $33 \mathrm{~mm}$ long specimen than the 66 $\mathrm{mm}$ long one. Consequently, the heating time depends on the ambient temperature and the volume of parts to which the Ni-Ti wire is connected. 


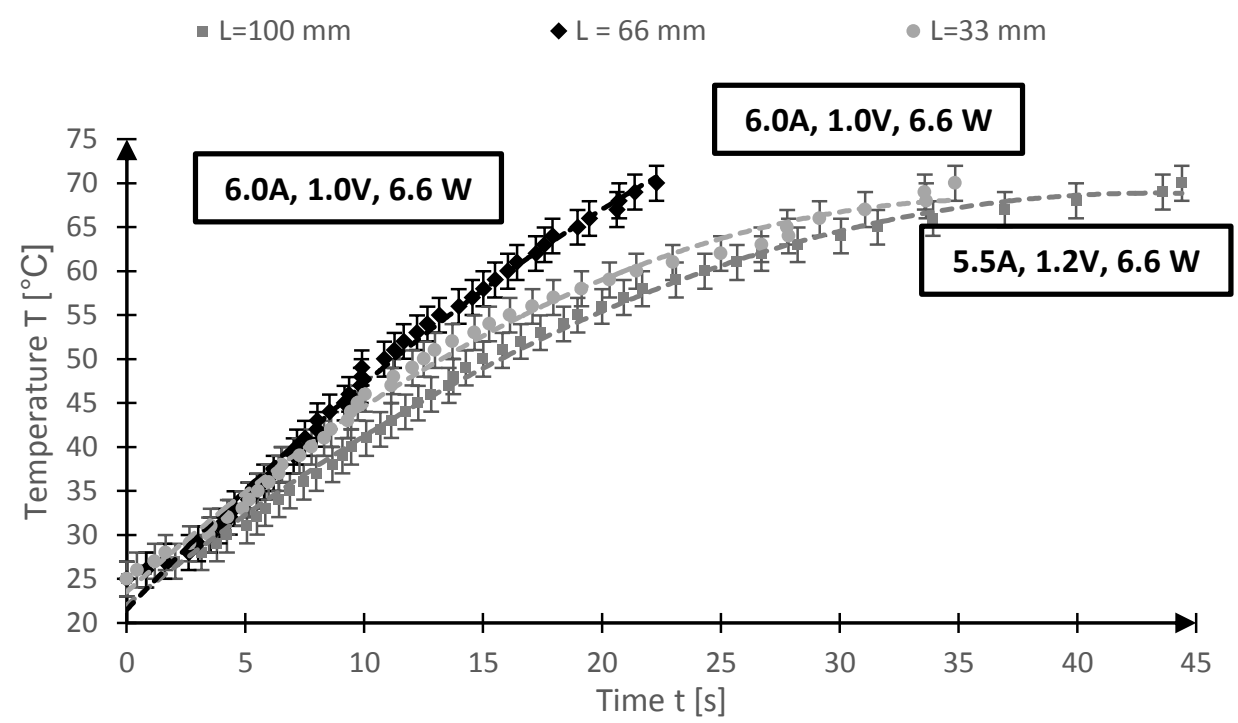

Fig. 3. Time-temperature curves for $100 \mathrm{~mm}$ and $66 \mathrm{~mm}$ long specimens

Fig. 4 presents the time-temperature curves obtained in heating $100 \mathrm{~mm}$ long specimens of Ni-Ti alloy up to the activation temperature at different power input levels. Heating the specimens with $6.5 \mathrm{~A}$ and $1.2 \mathrm{~V}$ current $(9.75 \mathrm{~W})$ produced time-temperature curves having a curved (bulged) shape. Higher values of current make the curve more linear, allowing determination of the trendline slope. The trendline slope depends on the level of power applied to the Ni-Ti wire. For input powers above $10 \mathrm{~W}$ the curve can be treated as linear. There is over $98 \%$ match between the trend line established for such power inputs and the experimentally determined curve. This approximation allows us to assume possibility of modelling the behaviour of nitinol wire specimens as a function of their length and power input level.

The test results were used to draw the curve representing the effect of power input on the time needed to heat up the specimen to the activation temperature. The obtained curve was subjected to linearization following determination of slope as a function of time. The slope depends on the values of applied current and voltage. Thus, by controlling these parameters we can control the behaviour of the specimen made of NI-Ti alloy. Over $99 \%$ fit is established between the experimental values and the values obtained with the function of slope variation vs. input power. The graph in Fig. 5 presents the variation of the trendline slope as a function of input power. 

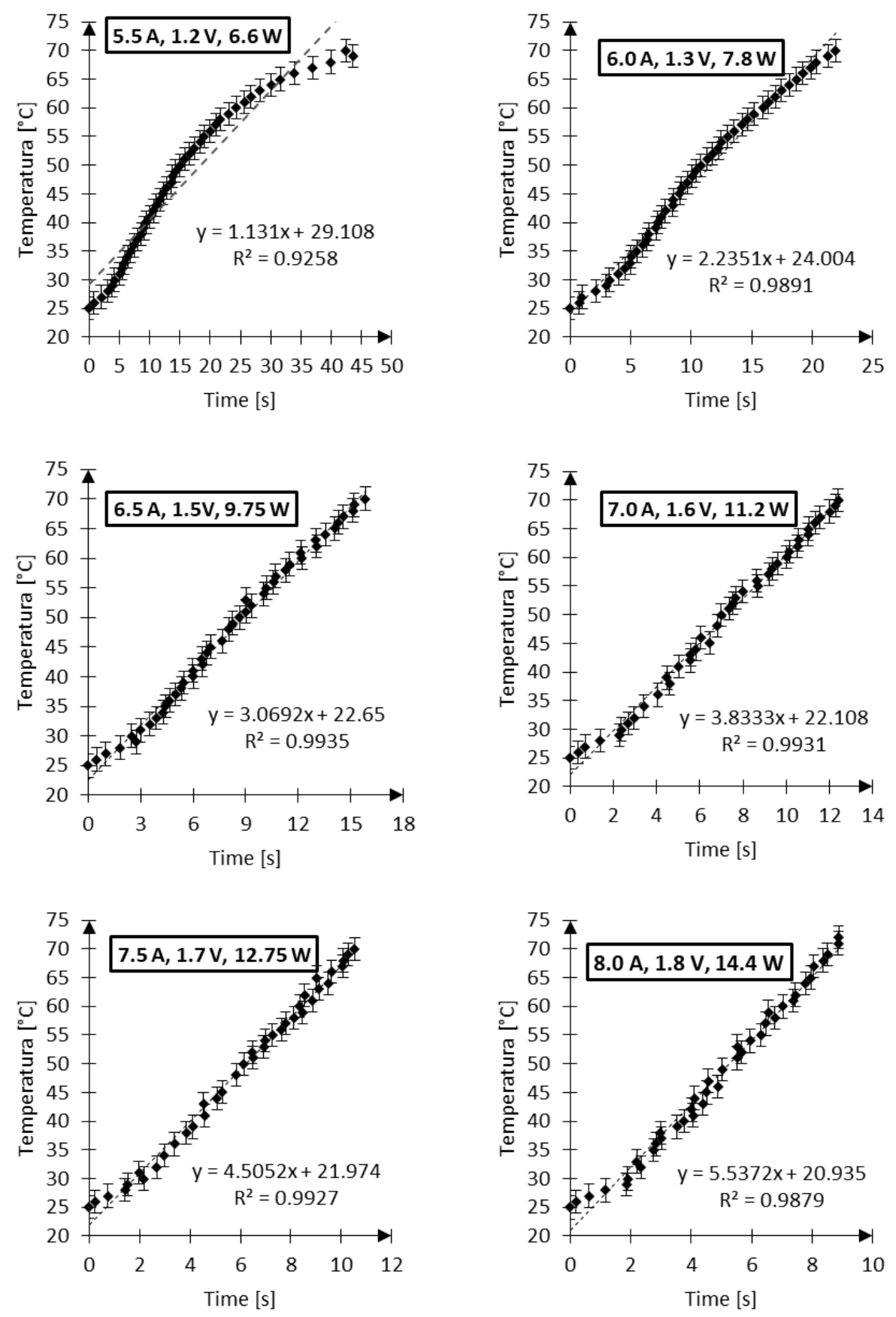

Fig. 4. Time-temperature curves obtained for $100 \mathrm{~mm}$ long specimens of Ni-Ti alloy depending on the heating time at different power input levels 


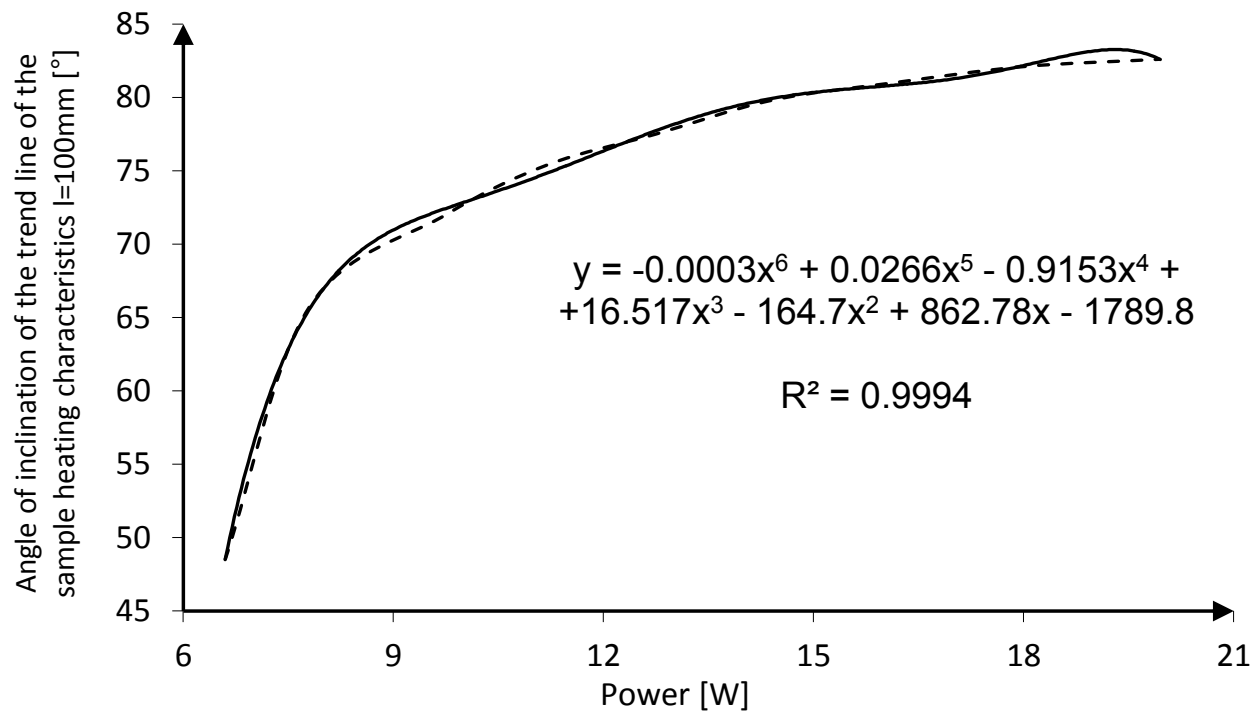

Fig. 5. Variation of the trendline slope as a function of input power

The experiment included also evaluation of the effect of low input power values (not exceeding $9 \mathrm{~W}$ ) on the degree of bulging (curvilinearity) of the time-temperature curve. Such bulging of curve for low input power levels results from ineffective heating of the specimen with excessive loss of heat in the final stage of the heating process. This was caused by too small current which did not made up for the heat losses determined by the test stand elements and by the ambient temperature of ca. $23^{\circ} \mathrm{C}$. That the curved shape (bulging) of the time-temperature curve can be attributed to insufficient current can be confirmed by comparing $100 \mathrm{~mm}$ and $66 \mathrm{~mm}$ long samples (Fig. 6). The time-temperature curves (Fig.6) show that with the decreasing volume of specimen smaller currents become more effective.
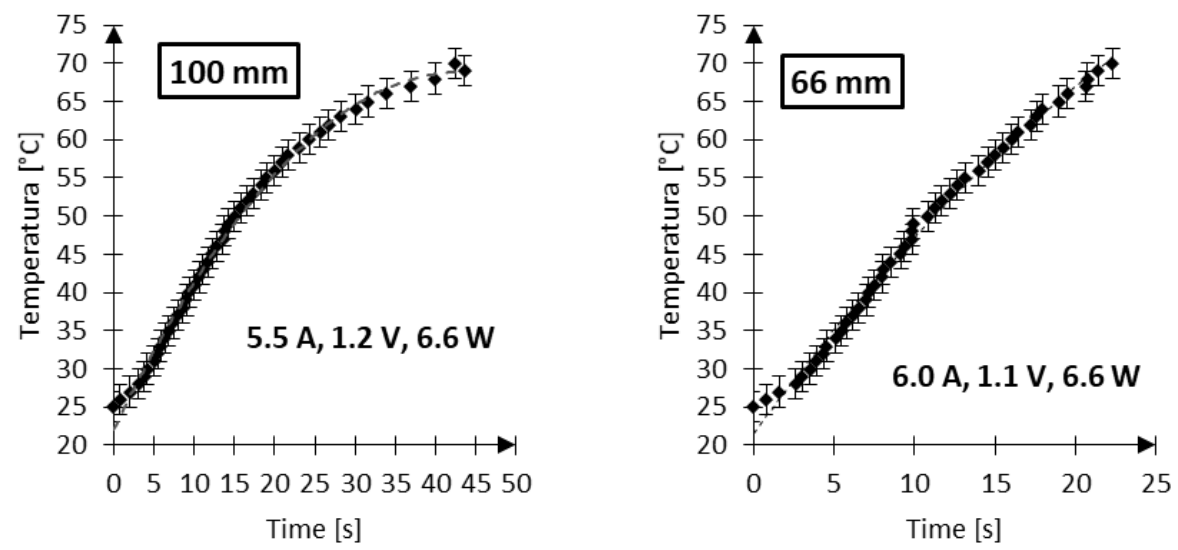

Fig. 6. Time-temperature curves for Ni-Ti alloy specimens heated by passing current of $6.6 \mathrm{~W}$ 


\section{Conclusions}

The present experimental research has demonstrated that the heating time strongly depends on the volume of the specimen and its mounting fixtures, as well as on the ambient temperature. The shape of specimen is yet another factor influencing the heating time and this is associated with the mechanism of heat dissipation to environment [5].

This preliminary research can be used as the first step on the way to develop a mathematical model representing the relationship between the temperature of Ni-Ti alloy wire and the heating time and also the input power. The objective of this research was to find the effective current and voltage enabling linearisation of the obtained curves. This approach enables building a mathematical model based on the slope coefficient of the trend line, representing the relationship between the temperature and the heating time for a given power input and the length of specimen.

The results can be useful in designing control systems of mechatronic systems equipped with SMA actuators. The curves obtained in this research enable selection of times required to achieve the specified temperature of activation (Af) at specific power input levels. The collected data enable estimating the values of constants used in already existing models representing the process of heating resistance wires by passing current [6].

\section{References}

1. W. Kucharczyk, A. Mazurkiewicz, W. Żurowski, Nowoczesne materiaty konstrukcyjne. Wybrane zagadnienia. Politechnika Radomska (2011)

2. A. Ćwikła, Medical applications of intelligent materials. Scientific Bulletin of Chelm Section of Technical Sciences, 1 (2008)

3. G. Markiewicz, Materialy inteligentne - zastosowanie w systemach aktywnej redukcji hałasu i drgań. Bezpieczeństwo pracy, 12 (2015)

4. S. Bohua, Smart materials and structures. Lecture at Swiss Federal Institute of Technology Zurich (ETH), Zurich (2015)

5. K. Biereg, Porównanie wybranych równań konstytutywnych stopów z pamięcia ksztattu. Modelowanie inżynierskie 32, p. 38, (2006)

6. A. Bellini, M. Colli, E. Dragoni, Mechatronic Design of a Shape Memory Alloy Actuator for Automotive Tumble Flaps: A Case Study. ieee transactions on industrial electronics 56 (7), 2644-2649 (2009) 